\title{
Research on International Trade Teaching in Higher Vocational Colleges from the Perspective of Cross-Border E-Commerce
}

\author{
Deru Qin* \\ Jiangsu Maritime Institute, Nanjing 211170, Jiangsu Provinces, China \\ *Corresponding author: Deru Qin, njqinderu@126.com
}

\begin{abstract}
Higher vocational education's international trade major is one of the most significant majors in current vocational education's popular talent training. Introducing the thinking and mode of cross-border e-commerce, as well as effectively establishing a talent training mode based on career orientation, will not only contribute to the scientific and standardized development of contemporary vocational education, but will also create a new situation in the process of international trade. The effect of talent training is ensured by the new curriculum development method of higher vocational education in the new era ${ }^{[1]}$. This article briefly discusses the training direction and route of international trade professionals from the perspective of cross-border e-commerce, with the goal of making a little contribution to the training of current professional talents.
\end{abstract}

Keywords: International trade; Cross-border e-commerce; Teaching research

Publication date: December 2021; Online publication: January 24, 2022

\section{Introduction}

Higher vocational education is an essential step in China's talent development. Both the curriculum system and training methods in higher vocational education should be guided by professional needs, with professional ability as the actual training goal, and professional training for talents carried out through scientific curriculum design and diversified teaching methods, multimodal practical operation, and other means, in order to effectively enhance their professional ability and professional quality, as well as their comprehensive strength.

\section{Scientifically implement investigation and analysis, rationally construct curriculum system}

\subsection{Scientifically establish the training direction of students under the guidance of market demand}

We should scientifically develop the training direction of students under the supervision of market demand in the training of international trade experts in higher vocational colleges from the perspective of crossborder e-commerce ${ }^{[2]}$. On the basis of defining the market requirement of professional equivalents, higher vocational schools should decide the professional connotation and direction. In particular, it is to comprehend the post-demand and employment demand of international trade majors from a cross-border perspective in order to establish a scientific positioning for talent training, then to develop students' training ideas and systems based on professional standards and grades, to put forth reasonable curriculum development suggestions, and to effectively and comprehensively train international trade professionals. Professional teachers should establish professional research teams in higher vocational colleges to forecast actual demand for international trade professional training from a professional standpoint, and then analyze the development prospects of international trade professionals through detailed research on the 
development of modern enterprises, industries, brother colleges, and markets. Determine the professional talent training objectives to fulfil the market's future development demands on the basis of continual scientific demonstration.

\subsection{Build a talent training system around practice}

The fundamental aim of students in an international trade teaching course based on work process is to study and master the professional knowledge and skills of international commerce through various learning methods. The school should scientifically guide students through various teaching methods, such as the establishment of a project-based curriculum system, so that students can first make scientific learning and work task plans in the process of specific learning and practice, systematically analyze the constituent factors and implementation steps to be mastered, and then integrate theory with practice in the process of implementation.

\subsection{Comprehensively cultivate ideas through skills and knowledge}

The training of international trade professionals from the perspective of cross-border e-commerce should not aim at simply teaching international trade skills and knowledge, but should focus on teaching students corresponding learning concepts and methods. The curriculum system and teaching should be guided by the specific work process. Through the design of different work situations and work demand situations, students can constantly strengthen and understand the practical and theoretical knowledge they have learned and mastered in the process of practical operation. This action orientation based on talent training is not a specific teachable teaching method, but a guiding ideology or strategy based on a certain demand and action or to achieve a goal, which can be embodied in one or several different teaching ideas or methods ${ }^{[3]}$. Such as case teaching method, project teaching method and task driven teaching method. In the specific actionoriented teaching mode, the corresponding teacher will no longer be a teacher of skills and knowledge, but should be an interrogator, an organizer and a bystander providing guidance. Through this mode or way, students' learning becomes discussion, and students' practical operation becomes practical creation. In this process, students' skills and knowledge will become more stable and diverse in practice. In addition, in the specific process of teaching, the school should also actively pay attention to the scientific evaluation of students in terms of talent training, and then conduct more detailed guidance to students through scientific evaluation, enhance students' self-demand, inquiry consciousness and learning, and improve their comprehensive quality.

\section{Implement diversified teaching and training mode to ensure the training effect of students}

\subsection{Construct mixed teaching mode}

Split classroom teaching is an essential aspect of students' scientific education and instructors' scientific planning of instructional activities in today's classrooms. It is crucial in encouraging students to scientifically grasp new skills and knowledge acquisition methods, to improve their knowledge acquisition path and efficiency, and to improve their overall quality. According to some data, the proportion of network assisted teaching after class in higher education is as high as $72 \%$, and the number of students who independently acquire skills and knowledge through the network is as high as $87 \%$ stage of higher education, particularly in COVID-19. Even in some industrialized countries, almost $95 \%$ of students have met their own knowledge requirements. Take the initiative to learn the necessary skills and information from the expert via an online learning platform. As a result, in the teaching of international trade, vocational colleges and teachers should actively introduce advanced ideas and methods of classroom teaching, such as online and offline hybrid, bisection, and flipping, to effectively improve the training effect of students, ensure the 
teaching efficiency of skills and knowledge, and allow students to test whether their skills, both knowledge and acquisition methods, can be improved and developed in a limited learning time ${ }^{[4]}$.

Teachers can, for example, use the online class platform, vocational education cloud platform, or micro class platform on the Internet to actively find and create advanced corresponding professional courses and teaching cases in order to attract students' attention, and then insert some familiar patterns or elements into them. After students have a good understanding, divide them into several inquiry groups, and have them conduct in-depth excavation and effective discussion on relevant economics problems and knowledge. This will improve their inquiry consciousness, stimulate inquiry thought, and allow them to gradually build a new learning model and their own knowledge acquisition strategy, as well as improve their overall learning literacy. Teachers should pay attention to students' learning ability and literacy in specific teaching, and actively use online education and other means to scientifically guide students to preview and problem exploration, so that they can obtain corresponding skills and knowledge from me through various network platforms under the awareness of autonomous learning, in order to improve their learning literacy and comprehensive level.

\subsection{Adopt cloud platform teaching methods}

Cloud platform education is a cutting-edge educational mode in the modern Internet era, with its primary operating mode based on big data analysis and interpretation. It means that after teaching basic classroom knowledge and skills, teachers can allow students to complete corresponding exercises on a better cloud platform, which can scientifically analyze and explore the benefits and drawbacks of students' actual skills and knowledge based on comprehensive data such as the difficulty, incorrect questions, and answer time of students' corresponding exercises. To assist students in scientifically identifying their own learning deficiencies, checking and filling in the gaps in the relevant supplemental and targeted tasks provided on the cloud platform, and successfully completing the in-depth acquisition and firm mastery of skills and information. The cloud platform mode is a novel approach to modern Internet-assisted education. It not only disrupts the original educational ecological mode, but it also efficiently improves and develops students' comprehensive ability by enhancing their comprehensive learning literacy. Teachers can, for example, use various teaching and research platforms to guide and educate students and stimulate their interest in the knowledge to be learned, and then use micro classes to guide students to study and study the corresponding knowledge plates step by step, with the assistance of an Internet real-time communication system ${ }^{[5]}$. Collaborate in groups, do online research and analysis, and scientifically learn the relevant information. Following the preview, teachers can reply to queries and address difficulties raised by students in class, as well as provide focused explanations and accompanying activities tailored to the requirements of the majority of students. Following class practice, teachers should direct students to the appropriate education cloud platform, where they can conduct targeted evaluation and analysis using the platform's big data analysis mode, thereby enhancing their own literacy and completing the comprehensive grasp and systematic explanation of corresponding skills and knowledge.

\subsection{Build a diversified evaluation system}

Students may use a scientific assessment system to not only master their professional curricular skills and information, but also to assure their learning efficiency and improve their overall quality. Based on this, teachers should not only actively adopt diversified and diversified teaching methods in the training of international trade professionals, but also implement diversified curriculum knowledge and skills, as well as a student literacy and ability evaluation system, from the perspective of students' self-development and according to the actual situation of students. Teachers can assess students from three various points and 
orientations in this design, paying special attention to process assessment and comprehensive assessment, to assure the scientificity and efficacy of assessment and successfully improve students' overall quality. The first is daily assessment, which entails using basic evaluations in daily instruction to scientifically comprehend students' real learning effects and then providing focused explanations to assist students master knowledge and enhance their learning literacy.

The second is final evaluation. That is, students' knowledge intensity and density will be tested and evaluated so that they may stop being lazy on a regular basis. The final step is comprehensive evaluation, which entails combining comprehensive scoring with daily classroom learning, experimental learning, and after-school evaluation in order to help students recognize their learning position and make purposeful efforts and development in an effective and scientific manner. In addition, numerous schools have increasingly reinforced the building of students' ideological and political education in recent years, resulting in new standards for ideological literacy and consciousness levels of talents. Teachers should incorporate some ideological and political material into assessment instruction, actively use social hot topics to test students' ideological knowledge, and successfully increase their ideological and political learning literacy as a result.

In short, in order to effectively ensure the training efficacy of international trade professionals from the perspective of cross-border e-commerce, teachers should combine the current situation of the school and the development of students, under the core principle of student-centered and seeking truth from facts, and actively adopt diversified and diversified teaching modes to scientifically train students from the future development direction of the discipline, and actively adopt diversified and diversified teaching modes to scientifically train students from the future development direction of the discipline.

\section{Disclosure statement}

The author declares that there is no conflict of interest.

\section{References}

[1] Liu HY, 2021, Research on the Teaching Reform Path of International Trade Specialty under the Background of Cross-Border E-Commerce. Pr World, 2021(22): 123-125.

[2] Ding XR, 2021, Practical Teaching Reform of International Trade Practice Specialty in Higher Vocational Colleges under the Background of Industry Education Integration. Foreign Trade and Economic Cooperation, 2021(10): 153-156.

[3] Lin J, 2021, Discussion and Construction of Teaching Reform of International Trade Practice in Higher Vocational Colleges. Marketing, 2021(29): 93-94.

[4] Liu Y, Chen FJ, 2021, Research on Teaching Reform of International Trade Practice under the Background of Cross-Border E-Commerce. Marketing, 2021(38): 92-93.

[5] Chen X, 2021, Reflections on International Trade Teaching in Higher Vocational Colleges from the Perspective of Cross-Border E-Commerce. Teacher, 2021(15): 97-98. 